\title{
Self-efficacy and anxiety as determinants of older adults' use of Internet Banking Services
}

\author{
Begoña Peral-Peral, PhD. bperal@us.es +34 954554431 \\ Ángel F. Villarejo-Ramos, PhD. curro@us.es +34 954554463 \\ Jorge Arenas-Gaitán, PhD. jarenas@ us.es +34 954554427
}

Business Administration and Marketing Department, University of Seville, Spain

The second-level digital divide presents differences in people's capabilities of using information and communication technologies (ICT), especially in older adults. This paper focuses on exploring self-efficacy and anxiety in this group concerning the use of a specific e-service, internet banking service (IBS). Considering the triadic relation proposed in Social Cognitive Theory (SCT), we include in the model of IBS use by older adults personal characteristics, such as self-efficacy, anxiety, perceived usefulness and gender with respect to the e-service chosen. We analyse the effect of perceived risks and social influence on these self-perceptions as environmental factors. This study is centred on a survey of 474 older adults, and tests the structural model proposed using PLS-SEM. The results show that there are important differences between self-efficacy and anxiety when we refer to technology in general compared with a specific e-Service. Furthermore, selfefficacy positively influences the perceived usefulness and the use of IBS. We note an 
important role of the environment as a booster to overcome the barriers which may appear due to these self-perceptions. Finally, we find influences of older adults' gender in the relationship put forward in the causal model.

\section{Introduction}

In the last two decades, information and communication technologies (ICT) have been one of the great pillars upon which people's welfare rests (Kavathatzopoulos, 2015). Nevertheless, different access to ICT has produced what is known as the digital divide, defined as "the gap between individuals, households, businesses and geographic areas at different socio-economic levels with regard both to their opportunities to access information and communication technologies (ICT) and to their use of the Internet for a wide variety of activities" (OECD, 2001, p. 5). Dewan and Riggins (2005) propose two levels of digital divide: the first-level refers to the inequality of access to IT, such as access to computers in homes and schools, and the second-level refers to the capability of using electronic services.

The basis of this second-level digital divide is that the progressive universalization of access to the Internet is not enough to guarantee people using it in the same ways, or their skills and capabilities when using e-Services stemming from ICT. This has led to the appearance of new divisions between users caused by the unequal distribution of technology capabilities and digital competences (Tsai, Shillair, Cotton, Winstead and Yost, 2015; Valenduc, Brotcorne, Lotte Damhuis and Vendramin, 2010).

Very different variables have been used to identify the so-called second digital divide: gender and age (Friemel, 2014; Niehaves and Plattfaut, 2014), the level of 
education/knowledge (Van Deursen and Van Dijk, 2011; Vošner, Bobek, Koko and Krečič,2016), psychological differences (Peral-Peral, Arenas-Gaitán and Villarejo-Ramos, 2015), socio-demographic differences between countries (Büchi, Just and Latzer, 2015) and, even social characteristics, such as being migrants (Barth and Veit, 2011). Age is one of the most interesting variables. The aging of the population is noted, fundamentally, in the more developed countries. The data of the «World Population Prospects» indicate that the number of people over 60 years old will double in 2050, reaching 3,100 million in 2100 (United Nations, 2017). It is also a question of one of the segments considered most out of touch with ICT (Eurostat, 2016), so its e-inclusion is a concern of diverse institutions (e.g., European Commission, 2016; International Telecommunication Union, ITU, 2015, p. 1112; World Economic Forum, 2016).

Our study focuses on the influence of some of these variables, self-efficacy and anxiety, added perceived usefulness and gender, as personal factors which are determinants of the model of use of e-Services in the case of older adults. Social influences and perceived risk are, as environmental factors, also included in the model. People's behaviour when using ICT is influenced by how they believe others perceive them to be using them. On the other hand, perceived risks have a negative effect on the acceptation of ICT.

An e-service implies that the customer's interaction or contact with the organisation is through the technology (Rowley, 2008), such as the web site or app. In e-service customers must learn from the interface, so their capabilities (personal factors) are very important, as is learning from others' experiences (environmental factors). The e-Service chosen to carry 
out the research is internet banking service (IBS), for various reasons: (1) it is a service that can be provided without personal contact and without bank offices; (2) due to its effect on the development of e-commerce in general; (3) because it is one of the most beneficial for financial bodies and enables a greater knowledge of the clientele; (4) as a result of the world trend to growth in banking operations through Internet; and (5) because of the progressive reduction of the number of bank offices, which means transferring many transactions to the online channel. If we add that the penetration rate of this e-service is lower for older adults, we consider it interesting to go deeply into the knowledge of how they behave in an IBS. Nonetheless, the model proposed can be applied to any other eService, as the self-perceptions employed can be adapted to the characteristics of any online service.

We propose various sub-objectives: 1) to explore the concepts of self-efficacy and anxiety concerning technology in general and those related to IBS, going thoroughly into the validity of differentiating between both types of self-perceptions and how they influence each other; 2) to analyse the environment's influence on self-efficacy and on anxiety, and, through these concepts, on the use of IBS; 3) to analyse the direct and indirect influences of these personal perceptions of technology on the use of IBS; and 4) to determine the role of gender and its influence on the relations of the model proposed.

Our study makes various contributions to the previous literature. Firstly, most studies which analyse the acceptation of new technologies in the marketing area are based on TAM (Technology Acceptance Model; Davis, 1989) or on UTAUT (Unified Theory of Acceptance and Use of Technology, Venkatesh, Morris, Davis and Davis, 2003; Venkatesh, Thong and $\mathrm{Xu}, 2012$ ), which are focused on the information system's characteristics. The 
model which we propose is based on Social Cognitive Theory (SCT) (Bandura, 1986;

Featherman and Hajli, 2015; Tsai et al. 2015), which emphasizes users' characteristics.

Secondly, we highlight our main contribution. There are previous studies which independently analyse self-efficacy (e.g., Wei, Teo, Chan and Tan, 2011) and anxiety (e.g., Guo et al., 2013), and others study both elements (e.g., Chen and Chan, 2014). Our paper, in addition to analysing the effect of both variables, studies how they interact and differentiates these concepts between those which are related to technology in general and those concerning one e-Service in particular (IBS). In this way, our study attempts to explain how the perception that one can use ICT in general influences the self-efficacy of using IBS and explains the level of the influence of anxiety.

Thirdly, this study, unlike many studies about e-Services which are centred on other age ranges, such as young people (e.g., Hill, Beatty and Walsh, 2013), or the public in general (e.g., Featherman and Hajli, 2015), is focused on older adults and their behaviour as users of e-Services. In this paper we define older adults as those over 55 years old, as some researchers suggest (Chung et al., 2010; Sum, Mathews, Hughes and Campbell, 2008).

In the same way, most of the work on the use of e-Services for older adults has focused on Anglo-Saxon or Asian countries, with some exceptions (e.g., Macedo, 2017; Peral-Peral et al., 2015). Therefore, this study contributes to expanding the geographic scope in this topic by applying it to a sample in a European Mediterranean country. Lastly, from a methodological point of view, our study has considered the indirect effects of the exogenous variables on the endogenous variables. 
The structure of this paper is as follows. The second section reviews the literature. This is the basis for the hypotheses of the model to be tested. The third section describes the most relevant aspects of the methodology used, describing the sample and justifying the measurement scales used. In the fourth section, we present the main results of the empirical study. Section 5 discusses the results obtained, linking them to the objectives proposed and to the previous literature and highlights the theoretical contributions of the paper. We finish the study by offering its main practical implications for society and industry. The last section presents the conclusions and suggestions for future research.

\section{Literature review and hypotheses}

\subsection{Social Cognitive Theory (SCT)}

Social Cognitive Theory (SCT) proposes that a person's behaviour is self-regulated through the forming of expectations about obtaining certain results. These cause people to behave in ways which affect their later emotions and thoughts (Bandura, 1997). Self-efficacy is the SCT's key concept. This is defined as people's beliefs concerning their capability of performing a specific task. These perceptions are specific to the task and to the particular situation, and are used to predict the success of carrying it out. Self-efficacy influences decisions concerning which behaviours to use, how much effort to make and the outcome expectations of obtaining a specific result when performing a task (Bandura, 1978). A high level of self-efficacy facilitates the cognitive process and improves the performance of multiple forms, such as the decision-making quality and goal achievement (Bandura, 1997).

To form self-efficacy, a person can use four sources: mastery experience, vicarious experience, social persuasions and psychological states. Mastery experience is the 
interpretation of the results obtained in the past (Bandura, 1997). Normally, if the results are interpreted as successful, self-efficacy increases. If they are perceived as failures, selfefficacy decreases (Pajares, 2002). Vicarious experience is defined as learning through observing the people who we consider to be role models. If they are successful in their activities, the belief that we also have the capacities necessary to achieve success increases. Social persuasions, which we receive from the people who are important for us, can strengthen our beliefs in being successful in a task. This positively influences the effort applied. Finally, psychological states, such as anxiety, depression or stress, affect the confidence that we have in our capacities, reducing our self-efficacy. On the other hand, positive emotions can increase confidence in our skills. According to Bandura (1997), the first two sources are those which have the greatest influence on the creation of selfefficacy.

SCT (Bandura, 1986, 1989) suggests that there is a triadic reciprocity between the person, the environment in which this person operates and this person's behaviour. The interactions of these three concepts produce different situations which influence human behaviour.

Some authors have employed the SCT framework in their research. For example, related with the use of computers, Compeau and Higgins (1995) assume that adopting and using a technology depends on people being convinced that they have the skills to be successful using it. These perceptions, or computer self-efficacy, can be used to predict the acceptance and use of systems (Venkatesh and Davis, 1996), to know why they continue being used and how to get high success rates (Torkzadeh and Van Dyke, 2002). If the successive interactions with the technology are satisfactory, these will result in a greater self-efficacy, thus fulfilling the reciprocal relationship between the person's cognitive characteristics and 
the person's behaviour. Wei et al. (2011) also use the term computer self-efficacy, in their model based on SCT. They analyse computer usage patterns including in their model personal factors such as gender, academic ability, and computer self-efficacy, and environmental factors such as the availability of computer resources and various sources of social cognitive influence (e.g., mastery experience, vicarious experience, social persuasions, and psychological states). Contextualized in this study, we introduce in the model personal factors such as self-efficacy, anxiety, perceived usefulness and gender; perceived risks and social influence as environmental factors; and test the model on the use of IBS.

Next, we will review the literature to propose the hypotheses of the model of IBS use by older adults, presenting them according to how they link personal, environmental and behavioural variables (Tsai, 2014; Wagner, Hassanein and Head, 2010).

\subsection{Personal attributes}

\section{Self -Efficacy}

Self-efficacy is the core of social cognitive theory. Yet, the measures of self-efficacy must be adapted to the topic of interest to maximize their prediction capacity (Bandura, 1986). For this reason, different terms are proposed in the literature. Thus, in the context of older adults, Lam and Lee (2006) and Tsai et al. (2015) define technological self-efficacy as people's beliefs in their skills to use technologies, and Eastin and LaRose (2000) study internet self-efficacy, defined as a person's beliefs about successfully performing the behaviours required to efficiently use the Internet. For a wide age range, Akhter (2014) also uses the term internet self-efficacy to check its positive effect on the frequency of online 
transactions and on the decrease of privacy concerns. Lankton and Wilson (2007) analyse self-efficacy associated with a health e-Service with a sample in a range of 24 to80 years old. They are concerned with people's judgments of their capabilities of obtaining certain performance levels when they use an e-health service. For high school students, Chen, Hsiao, Chern and Chen (2014) propose academic self-efficacy.

On the other hand, there are previous studies in the literature which consider two types of self-efficacy: one which has a more general content concerning technology and another which is specific and typical of the use of a specific system (Powell, 2013). Marakas, Johnson and Palmer (1998) suggest that general self-efficacy contributes to forming a specific task's self-efficacy, in such a way that this must be considered as a new variable in the adoption process (Eastin, 2002). Moreover, previous experiences with technology and their influence on people's self-efficacy will have a positive influence on the perceptions of the task-specific self-efficacy. Agarwal, Sambamurthy and Stair (2000) distinguish between general-computer self-efficacy and software-specific self-efficacy, defined as a person's perceptions of self-efficacy relative to a specific software package. With panel data, they show that both are linked, as previous self-efficacy with the software in general has an accumulative effect on the appraisal of self-efficacy using specific software. Hsu and Chiu (2004), with a sample with an age range of 21 to 56 years old, differentiate two aspects within internet self-efficacy, general internet and web-specific self-efficacy. The first is a trait-oriented efficacy and it captures a person's expectations about having the capability of satisfactorily carrying out tasks in a large variety of situations. The other is a state-based expectation and it represents the expectations measured immediately before making any 
effort to do the task and it is measured again after the use. Chu (2010) also proposes two measures for self-efficacy in the case of older adults, internet general and communication.

So, we propose the concept of IBS self-efficacy, defined as people's perceptions about their capability to successfully perform activities related to Internet Banking Services. And in the case of older adults, we enunciate Hypothesis 1.

Hypothesis 1: technological self-efficacy positively influences IBS self-efficacy.

\section{Anxiety}

Concerning ICT, some authors have analysed computer anxiety. This is defined as a person's apprehension, or even fear, when faced with the possibility of using a computer (Meuter, Ostrom, Bitner, and Roundtree, 2003; Venkatesh, 2000). It is considered to be a transitory state which fluctuates over time, can be modified via training and experience (Chua, Chen, and Wong, 1999) and can lead to negative impacts on the person's cognitive responses (Guo et al., 2013). Another concept studied is technology anxiety (NiemeläNyrhinen, 2007). This is linked to the use of technology and technological devices in general. Its effects are especially strong in the first phases of a person's process of adopting a new technology (Venkatesh, 2000) or when people use it for the first time (Gelbrich and Sattler, 2014).

Empirical evidence (Cazan, Cocoradã and Maican, 2016; Wu and Tsai, 2006) shows that there is a difference between general anxiety due to technology use and anxiety related to a specific system, so both variables must be used in models to analyse behaviour. Moreover, these constructs are linked. For example, access to the Internet requires the use of 
technology. Therefore, fear concerning using technology could be transferred to Internet use (Thatcher, Loughry, Lim and McKnight, 2007). Powell's (2013) study presents more than 30 articles in which different types of anxiety have been studied. She finds that both a situation's general anxiety and specific anxiety are positively linked to computer anxiety.

Older adults may be one of the groups immersed in the second- level digital divide (Tsai et al., 2015), given that it is more likely that older adults will experience a lot of anxiety in their ICT use (Wagner, Hassanein and Head, 2010). Thus, Powell (2013) noted that adult samples in the 2000s were significantly more likely to show a positive relationship between age and computer anxiety. Guo et al. (2013) indicate that older adults have greater technology anxiety than younger people, as they do not have the same level of education and experience with computers, although it seems that this anxiety is diminishing (Niemelä-Nyrhinen, 2007). Powell (2013:2365) points out that "it is worth noting that no studies have been conducted using seniors when studying the relationship of other anxieties and computer anxiety".

We therefore propose the concept of IBS anxiety, defined as people's apprehension when faced with using Internet Banking Services. This anxiety will depend on their technology anxiety, as previous experiences with technology will affect their perceptions of anxiety when using IBS.

Hypothesis 2: Technology anxiety positively influences IBS anxiety.

\section{Self-Efficacy and Anxiety}

Self-efficacy and anxiety are dynamic concepts: affective states. They are influenced by the factors of the environment (Marakas et al. 2000) and are specific to the person's situation. 
Bandura (1997) suggests that self-efficacy and anxiety are mutually and negatively influenced (Powell, 2013). Bandura (1988:77) proposes that "perceived self-efficacy to exercise control over potential threats plays a central role in anxiety arousal". Besides, it has been empirically demonstrated that self-efficacy is an antecedent of a person's anxiety (e.g., Cazan et al., 2016; Compeau, Higgins and Huff, 1999; Gelbrich and Sattler, 2014; Page, Robson and Uncles, 2012; Powell, 2013), although other authors have found the opposite direction (Barbeite and Weiss, 2004; Lee and Huang, 2014; Thatcher and Perrewé, 2002). In our case, as proposed by Bandura, self-efficacy negatively influences anxiety. In the case of older adults, age-related sensorial, cognitive and physical changes can affect their behaviour and impose restrictions on their capabilities. To maintain oneself active positively affects self-efficacy (Bandura, 1989). On the other hand, to doubt about your capabilities, leads to reducing your activities and to making less effort in the tasks you have decided to carry out. This causes a decrease of skills and greater anxiety. Technological self-efficacy and anxiety have been important barriers for older adults' technology adoption (Charness and Boot, 2009; Vroman, Arthanat, and Lysack, 2015) and are negatively related (Lam and Lee, 2006). It is therefore expected that self-efficacy, whether it be technological or system related, will reduce both types of anxiety. We thus propose Hypotheses $3 \& 4$.

Hypothesis 3: Technological self-efficacy negatively influences technology anxiety.

Hypothesis 4: IBS self-efficacy negatively influences IBS anxiety.

\section{Perceived Usefulness}

The concept of outcome expectations (Compeau and Higgins, 1995) is similar to the concept of perceived usefulness of Davis' (1989) TAM or the concept of performance 
expectancy of Venkatesh et al.'s (2003) UTAUT and has been used in different frameworks of technology acceptation and use. In the review that Venkatesh et al. (2003) carry out of a number of these models, this concept is the greatest predictor of behaviour intention. Compeau et al. (1999) prove in a longitudinal study the influence of computer self-efficacy on outcome expectations. These are defined as the degree to which you believe that using the system will help you to achieve gains in your work or in your daily life. Their results show significant links between computer self-efficacy and outcome expectations, and that both computer self-efficacy and outcome expectations impact an individual's affective and behavioural reactions to information technology. Neill and Richard (2012) consider that the relationship between Internet self-efficacy and perceived usefulness is most likely to reflect feelings of inadequacy or discomfort which may lead to demotivated users who cannot see the benefits in using the technology. They confirm the hypothesis that Internet self-efficacy positively influences the perceived usefulness of an intranet portal.

Concerning task-specific self-efficacy, it has been shown how academic self-efficacy influences academic performance in high school students (Chen et al., 2014) and that selfefficacy has a positive influence on perceived usefulness in the case of carrying out two activities - utilitarian and hedonic- via a tablet device, in the case of college students (Kulviwat, Bruner and Neelankavil, 2014). Hernández, Jiménez and Martín (2011) note the important role of self-efficacy as an antecedent of usefulness linked to online shopping, testing with a sample of a wide age range. Chen and Chan (2014) analyse gerontechnology self-efficacy or a sense of personal capability to successfully perform a given task, finding that it has a positive effect on performance usefulness in the case of older adults. 
We hence consider that IBS self-efficacy will positively influence people's perceptions that its use will enable them to gain usefulness or benefits in their daily life. The more confident and comfortable consumers feel with IBS, the more likely they will view it as useful. In the case of older adults, it is expected that this relation will also hold for them. We therefore propose Hypothesis 5.

Hypothesis 5: IBS self-efficacy positively influences perceived usefulness.

\subsection{Environment variables}

\section{Social Influence}

The notion that people's behaviour is influenced by the way in which they believe that others see them using technology has received terms such as subjective norms, social factors, social influence, image, and so on, in the different acceptation and use of technology models (Venkatesh et al. 2003). These variables, which are typical of the environment, may influence people's beliefs and their behaviour. This is due to their acting to fulfil group norms - friends, family, superiors (Bhattacherjee, 2001) - or because they feel social pressure to carry out a specific behaviour (Fishbein and Ajzen, 1975). Two of the factors which have an influence on the creation of self-efficacy are vicarious experiences and social persuasions. Both factors are very important when the person has little previous experience with the task and they are linked to social influence. In the first stages of the adoption process, when the level of uncertainty is greater, social influence affects people's behaviours. However, once their doubts have diminished, the effect of social influence lessens, ceasing to be significant as time goes on (Hsu and Chiu, 2004). Venkatesh et al. (2003) find that the constructs of social influence are significant in 
mandatory contexts, although they are not significant in voluntary contexts. Compeau et al. (1999) emphasize that for people to adopt a technology, coaching, teaching, and encouraging them is necessary to ensure that they have the skill and confidence required to be successful in its use.

Older adults could respond to opinions of others by modifying their judgments about their self-efficacy. The likely consequences of their behaviour would therefore be affected (Lam and Lee, 2006). Chu (2010) discovers how the family's tangible and emotional support plays an important role in the forming of older adults' self-efficacy. This is related with both the Internet in general and with the capability of communicating with others on the Internet. Chen and Chan (2014) propose that the encouragement and support of others can increase self-efficacy in older people. Tsai et al. (2015) find that older adults decide to acquire tablets after seeing others using them and due to the recommendation of friends and family.

We therefore propose that the positive influence of the closest environment - family and friends - will influence people's perceptions concerning their capability to successfully perform an IBS-linked task.

Hypothesis 6: Social influence positively influences IBS self-efficacy.

\section{Perceived Risks}

Perceived risks are a fundamental concept in consumer behaviour (Chen and $\mathrm{He}, 2003$ ).

This means that any actions of people could produce results that they perceive with a certain degree of uncertainty (Bauer, 1960). It is conceptualized as the likelihood of 
suffering negative consequences and includes a set of risks - financial, performance, social, psychological, safety, and time/convenience loss. Overall, perceived risk represents an aggregated impact of these various factors (Walker and Johnson, 2006) and, as it brings about anxiety in people, must be included in ICT acceptation models (Featherman and Pavlou, 2003). Any economic activity via the Internet implies possible losses of time, money and private information. This creates an environment which the consumer perceives as more uncertain and riskier than the simple use of the Internet, therefore anxiety due to the use of the specific system is greater (Celik, 2011). According to Forsythe et al. (2006), the continuous reports in the press about fraudulent activities which take place in e-Service activities, combined with the lack of personal contact, increase consumers' perceptions of risk. This makes them feel more anxious when carrying out electronic transactions.

Generally, researchers define perceived risk based on their own research contexts (Yao and Liao, 2011). Many studies have tested the influence of perceived risk on various innovation adoptions, such as internet shopping, e-Services, e-commerce and m-payment acceptance (Yang, $\mathrm{Liu}, \mathrm{Li}$, and $\mathrm{Yu}, 2015$ ). They find that perceived risks have a negative effect on the acceptation of these innovations. Bergström (2015) analyses the role that privacy-linked risks have on anxiety. Her results indicate that the greater frequency of use of the Internet is linked to less anxiety and that the effect on anxiety is greater when participating in activities such as social media and when using credit cards. This is in comparison with applications perceived as less risky, such as the use of e-mail or seeking information in the Internet. People with a greater fraud-linked anxiety are more reluctant to use an e-Service (Lee, 2009). 
Regarding older adults, Daman and Knapp (2015) point out how ICT can be perceived as a source of anxiety due to the risks of lack of privacy, fraud and identity theft. It has been found that older adults are more protective concerning their private data (Blank, Bolsover and Dubois, 2014; Bergström, 2015; Leppel and McCloskey, 2011). It is therefore to be expected that perceived risks related to the use of an IBS will influence anxiety when tackling this electronic system.

Hypothesis 7: Perceived risks positively influence IBS anxiety.

\subsection{Behaviour variables}

\section{Internet Banking Services Use}

As we commented before, the concepts of outcome expectations, perceived usefulness and performance expectancy have been considered as similar (Venkatesh et al., 2003). The previous literature has demonstrated their great influence on ICT use. Compeau et al. (1999) find that outcomes expectations affect computer use. In the case of older adults, the results of Lam and Lee's (2006) three-part longitudinal study confirm the impacts of expected outcomes on their intention to use computers. Nayak et al. (2010) show that, for older adults aged $60-88$, and for more complex Internet activities, perceived usefulness is a significant factor of the use. Given that perceived usefulness is one of the main predictors of the use of a technology (Davis, 1989; Kwon and Wen, 2010; Scherer, Siddiq and Teo, 2015; Venkatesh et al., 2003), we propose Hypothesis 8.

Hypothesis 8: Perceived usefulness positively influences IBS use. 
Meuter et al. (2003) propose that technology anxiety is the main determinant at the individual level of the use of a technology. One of its consequences is resistance to change, given that those people who have high levels of anxiety tend to be more concerned about unexpected mistakes caused by technology. This is why they will try to maintain the initial status quo (Guo et al., 2013), although technology anxiety can be reduced by training and experience (Zhao, Mattila and Tao, 2008). Powell's (2013) review shows that the link between anxiety and use has been studied by numerous authors who have found a negative relation between the two concepts.

As for older adults, Czaja et al. (2006) discover the negative effect of computer anxiety on their computer use. Guo et al.'s (2013) result implies that anxiety can activate the inhibitors of use, such as resistance to change. Chen and Chan (2014) analyse gerontechnology anxiety, finding a negative effect on use of the system. Therefore, we propose Hypothesis 9.

Hypothesis 9: IBS anxiety negatively influences IBS use.

We present below the proposed model in which the hypotheses that will be tested in the work are represented (Figure 1):

Figure 1: Proposed Model

Lastly, there is evidence of a gender-based digital divide. Sun and Zhang (2006) state that men are more pragmatic, while women experience greater anxiety when faced with new activities and are more strongly influenced by their immediate environment as a social influence. In the ICT environment, gender affects variables such as performance usefulness, 
self-efficacy and subjective norms (Venkatesh and Morris, 2000) and explains the differences in terms of web/internet/e-Service participation indicators. Likewise, it has been found (Page et al., 2012) that women report lower internet skill levels, exhibit higher levels of discomfort in their online activities and perceive the web as less useful than men web users do. Powell (2013) finds that women and older people are more likely to experience anxiety than those who are men or younger. Lee and Huang (2014) note that computer anxiety may lead to lower self-efficacy more often in the case of women than in the case of men. Wagner et al.'s (2010) review and Damant and Knapp (2015) found that men experience less computer-related anxiety and have more positive attitudes than women, in the context of older adults. The greater anxiety of women may stem from their having a greater level of emotional responses, the roles associated with each gender and because women pay more attention to hedonic benefits (Cazan et al., 2016). Due to all this, it is to be expected that significant gender-based differences will take place in the relations proposed in the model of IBS use, especially in the context of older adults. We therefore add the last hypothesis.

Hypothesis 10: There are differences in the relations proposed in the model due to the gender of older adults.

\section{Methods}

\subsection{Sample}

The sample was collected using students over 55 years old enrolled in a Class of Experience in a University in the south of Europe. This Class is a university programme of scientific, cultural and social development aimed at promoting science and culture in order 
to improve the quality of life of older people and encourage their participation in their context as social dynamizers. Data were collected through a survey in the academic course 2013-2014, during class, via a self-administered survey. The questionnaire was given on paper to the participants during one of their classes. The researchers were present to resolve any doubts that might arise. All the participants had knowledge about the Internet since they had passed an ICT basic course.

The initial research questionnaire was developed from well-validated instruments used in prior studies. A pre-test of this questionnaire was carried out with seven students who completed the questionnaire and provided feedback regarding their opinions about the questions. This led to a revision of the questionnaire. Finally, 576 questionnaires were obtained after a process of refining and eliminating the questionnaires which were incorrectly filled out. This led to 474 valid surveys. Table 1 shows a summary of the main characteristics of the sample.

\section{Table 1. Sample Description}

\subsection{Measurement scales}

All the scales have been adapted from previous research which had successfully used them before. Meuter et al. (2003), followed the proposal of Niemelä-Nyrhinen (2007), which identified the constructs of technological self-efficacy and technology anxiety. To measure IBS use we employed the scale proposed by Kwon and Wen (2010). Venkatesh et al. (2003) was our basis to measure self-efficacy and anxiety with IBS. Perceived usefulness and Social Influence were adapted from Venkatesh et al (2012). Concerning perceived 
risks, we adopted the proposal of Chen and He (2003) and Walker and Johnson (2006). In all cases, 7-point Likert scales were used.

The original instruments were in English, the questions were first translated from English into Spanish and a back-translation was done by translators who fluently speak the two languages. The back translation was compared with the English version of the questionnaires to identify any lack of fidelity and to find the most appropriate equivalents for the items adapted to the Spanish cultural context.

\subsection{Statistical Tool}

To test the structural model proposed we used PLS-SEM (Hair, Sarstedt, Hopkins and Kuppelwieser, 2014), specifically the SmartPLS 3.2.3 software (Ringle, Wende and Becker, 2015). The SPSS 23 software was used for calculating the descriptive statistics and the analysis of average differences.

\section{Results}

Structural equations modelling (SEM), as is the case of PLS analysis, has two steps: first the reliability and validity of the measurement scales are ensured; then the structural model itself is dealt with. Given the aim of our study, we have carried out a third step which does two multi-group analyses to know the moderating role of gender in the proposed model.

In the first step, following the guide provided by the previous literature (Fornell and Larcker, 1981; Henseler, Hubona and Ray, 2015), we analysed the reliability of the items and constructs, and their convergent and discriminant validity. To analyse the individual reliability of each item, their loadings must be observed. In all the cases they are above the 
0.7 recommended. Likewise, two indicators analyse the reliability of the constructs:

Composite reliability and Cronbach's Alpha. In both cases the values obtained are over the 0.7 recommended. To analyse the convergent validity, we used the average variance extracted (AVE). The results were over the 0.5 recommended (Henseler et al., 2015). All these results are shown in Table 2.

Table 2: Loadings, AVE, Composite reliability and Cronbach's Alpha

Two tests were successfully carried out to analyse the discriminant validity. First, we followed Fornell and Larcker's (1981) recommendations shown in Table 3. Here the square roots of the AVEs are in the diagonal. They must be greater than the correlations noted in their respective rows and columns. Table 4 also includes the heterotrait-monotrait ratio proposed by Henseler, Ringle and Sarstedt (2015), where all the values must be less than 0.9 and it would be desirable for them to be less than 0.8. This is our case. As a result of all this process to ensure the reliability and validity of the scales used, it was only necessary to eliminate two items in the scale on IBS self-efficacy.

\section{Table 3: Fornell-Larcker Criterion}

\section{Table 4: Heterotrait-monotrait ratio (HTMT)}

After having ensured the reliability and validity of the measurement model, we evaluate the structural model to test the hypotheses proposed. To do so, we have carried out bootstrapping with 1,000 sub-samples to check the statistical significance of each of the coefficients or paths and the variance explained $\left(\mathrm{R}^{2}\right)$ in the endogenous variables. We used the SRMS criterion to assess the model's goodness of fit. In our case this is 0.049 , less than the 0.08 proposed by Henseler et al. (2015). To continue with the aims proposed, we 
carried out a multi-group analysis, PLS-MGA, differentiating the sample by gender. Figure 2 and Table 5 show the results of the PLS analysis for the whole sample and by groups. In Table 5, the statistically significant results are shown in bold.

Table 5: Path Coefficients. Global and Multi-group Analysis.

Figure 2: Results PLS. Global and Multi-group Analysis.

To sum up, based on the results, the hypotheses $\mathrm{H} 1, \mathrm{H} 2, \mathrm{H} 5, \mathrm{H} 6, \mathrm{H} 7, \mathrm{H} 8$ and $\mathrm{H} 9$ are accepted. Hypothesis $\mathrm{H} 4$ is not accepted. Hypothesis $\mathrm{H} 3$ is partially accepted: no significant relation is found in the global sample, but relations do appear when we take gender into account. In this case the behaviours of men and women are very different. Following this last idea, we accept hypothesis H10, which indicates that there are genderbased differences, given that we have registered significantly significant differences in four of the nine hypotheses. The last two columns of Table 5 show the differences between men and women. To verify the difference between the two groups, we employed parametric and nonparametric tests. The nonparametric test (PLS-MGA) is recommended by Henseler (2012) because it does not require any distributional assumptions. Similar results were obtained. Specifically, we found significant differences in four (H1, H3, H4 and H8) of the nine hypothesised relationships.

Finally, to go more deeply into the results obtained, we have analysed the indirect effects of the exogenous variables on the model's endogenous variables. Following the multi-group analysis, this test has also been carried out, differentiating by gender looking for differences. The results are shown in Table 6. Specifically, we have found significant indirect (moderate) relationships between Tech Self, Tech Anx, IBS Self, Soc Influ, Perc 
Risks and our main dependent variable IBS Use. In this sense, we found significant differences between men and women in the relationships between Tech Self and Soc Influ with IBS Use.

\section{Table 6: Indirect Effects}

\section{Discussion}

In general, the results successfully endorse the aim of this study. Our main objective is to explain older adults' use of IBS. The model proposed is appropriate, considering the high number of hypotheses accepted, the results offered by SRMS and the high level of variance explained obtained by the endogenous variables, especially for older adults' IBS use. Next, we will explore the results for each of the sub-objectives proposed.

The first sub-objective proposed exploring the concepts of self-efficacy and anxiety linked to technology in general and those related with IBS. The results support the suitability of differentiating between more general self-efficacy and anxiety, both connected with technology, and others specific to the e-Service analysed (Cazan et al. 2016; Powell, 2013; Thatcher et al., 2007; Wu and Tsai, 2006). Both self-efficacy and technology anxiety are strongly linked to IBS self-efficacy and anxiety ( $\mathrm{H} 1$ and $\mathrm{H} 2)$ and to include them in the model improves their predictive power (Eastin, 2002). These hypotheses generally hold for both men and women, although there is a significant gender-based difference in the relation of Technological self-efficacy with IBS self-efficacy (Table 5): when men and women increase their self-efficacy with technology, they trust their skills more when facing IBS. However, the relationship is significantly stronger in men than in women. 
The relations proposed in the following two hypotheses offer very different results. In the case of the influence of technological self-efficacy on technology anxiety (H3), no significant relation has been found for the complete sample. It is interesting to analyse these global results, given that in this case we observe a high heterogeneity in the results due to gender. That is, when analysing men and women separately we observe that the hypothesis holds in both groups and also in a significantly different way (Table 5). Thus, in the case of men there is a negative relation between the two constructs, as the hypothesis maintains: perceived anxiety diminishes when there is a gain in self-efficacy. However, curiously, in the case of women this relation is positive. A possible interpretation of these results is that women are clearer about what their limits with technology are and are more pragmatic concerning their capabilities (Sun and Zhang, 2006). Therefore, although they gain in selfefficacy, anxiety continues being present (Cazan et al. 2016; Powell, 2013) and it is not easily reduced. In summary, the results that point to a non-significant relationship in the overall sample are hiding important differences in the behaviours of men and women that must be considered when developing technology adoption strategies.

In the case of self-efficacy and anxiety related with IBS, we do not find in any case a direct relation between them (H4). For the case of a specific, rather difficult technological system, it would be interesting to use the perceived ease of use concept. This is Venkatesh et al.'s (2003) proposal in their UTAUT model. They do not include self-efficacy and anxiety as they consider that these variables are indirect determinants of the intention of use through effort expectancy. In the same way, Tsai (2014) finds that ease of use is associated with the concept of self-efficacy. On the other hand, it is possible that the technology analysed has a powerful influence on the verification of this hypothesis. Thus, perhaps another type of e- 
service with lower perceived risks (i.e., online medical appointments) or with a more hedonic character (i.e., social networks sites) reflects a significant relationship between self-efficacy and anxiety.

Another possible explanation comes from the analysis of the indirect relations (Table 6), as we find that there is a significant indirect gender-based relation between technological selfefficacy and IBS anxiety. While men indicate a relation with a negative sign, women offer a positive indirect relation between the two concepts. That is to say, in the case of men their self-efficacy with technology reduces their IBS anxiety. For women the increase of their technological self-efficacy leads to greater levels of IBS anxiety.

Therefore, and with respect to the first sub-objective, it makes sense to differentiate between technological self-efficacy and IBS self-efficacy, the same as between technology anxiety and IBS anxiety. Moreover, we prove how significant gender-based differences in older adults are found in some of the relations presented.

The second sub-objective proposed analysing the influence that the environment has on self-efficacy and anxiety, and, through them, on the IBS use. The results indicate that the environment has an influence on personal beliefs. Social influence affects IBS self-efficacy (H6) and perceived risks affect IBS anxiety (H7). In both cases, the environment's influence is greater for women (Table 5) (Sun and Zhang, 2006), indicating that their perceptions of self-efficacy and anxiety are more affected by others and by the system's characteristics. Furthermore, analysing the indirect effects (Table 6), we find that the elements of the environment also significantly and indirectly affect the IBS use and the 
perception of its usefulness. In this case, there are no gender-based differences in the results. Men and women see themselves as being equally influenced by the environment.

The third sub-objective proposed analysing the influence of both types of self-efficacy and anxiety on IBS use. Thus, first of all, we verify that the influence of IBS anxiety on use (H9) is significant and negative. Older adults' anxiety when faced with IBS reduces their use. This also holds without gender differentiation. According to these results, anxietywith-IBS in general makes it difficult to use this technology, as stated in H9. Although the results make it clear that there are no differences between men and women, it is curious that this relationship is not significant in any subsamples. These latter results make us think that there may be moderating or mediating elements which explain it.

Secondly, we propose that IBS self-efficacy positively affects perceived usefulness (H5) and this latter influences IBS use (H8). Both hypotheses are accepted; gender-based differences being found in $\mathrm{H} 8$. Hence, men present a statistically significant greater relation between perceived usefulness and IBS use than women. That is to say, the greater their perception of the system's usefulness, the greater their use will be (Venkatesh and Morris, 2000). This is probably because women perceive ICT as being less useful than men do (Page et al., 2012) and because they pay more attention to hedonic benefits (Cazan et al, 2016) than to utilitarian benefits. Thirdly, we analyse the indirect relations (Table 6) of technological self-efficacy, IBS self-efficacy and technology anxiety with the model's endogenous variables. Important results are found. Technological self-efficacy positively, significantly and indirectly affects the perceived usefulness of the service and its use, both in the case of the whole sample and when differentiating by gender, although the relation is stronger in the case of men. IBS self-efficacy positively and indirectly influences use, while 
technology anxiety negatively and indirectly influences IBS use, in both cases without differentiating by gender. To sum up, both types of self-perceptions influence IBS use, either directly or indirectly. What is more, the relations have the sign expected: both kinds of self-efficacy positively affect the use of the system (Czaja et al., 2006; Hsu and Chiu, 2004), while both anxieties have an influence by reducing IBS use (Chen and Chan, 2014; Guo et al., 2013; Powell, 2013).

Finally, we proposed as a fourth sub-objective the analysis of gender in the model's relations. As we have noted throughout this section, significant differences are found between men and women. When men increase their technological self-efficacy, they trust their skills more when facing IBS and their perceived anxiety diminishes. Furthermore, if they perceive IBS as being useful, they increase their use more than women do. On the contrary, older women reflect greater levels of anxiety even when they improve their selfefficacy.

To conclude, we highlight the main contributions of this work to the theory. Instead of using technology acceptance models that focus on the characteristics of the information system, we used a SCT framework to analyse the use of IBS, which allows us to consider the personal characteristics (self-perceptions) and the influence of the environment. In addition, we have analysed: 1) the relationship between self-efficacy and anxiety, regarding technology in general and regarding IBS in particular; 2) how they interact with each other, analysing their direct and indirect effects on the model; and 3) how they influence IBS use. However, we believe that the proposed model can be used in other e-services, as well as tested in another type of population. The concern for the e-inclusion of the older adults and the analysis of their conditioners underlies the main purpose of the research. In our case, 
the chosen sample can condition the results, since it is active older adults, concerned about learning and active aging.

\section{Practical implications for society and industry}

The e-inclusion of older adults is a concern of numerous national and international public bodies. We have confirmed that self-efficacy and technology anxiety influence the behaviour of older adults, as well as the perceived usefulness of Internet Banking Services. Therefore, measures at a social level must be aimed at increasing self-confidence and reducing the anxiety regarding any e-service. In this sense, the environment surrounding older adults has a powerful influence. Firstly, the social influences of the closest environment (social persuasions according to SCT) can increase self-efficacy and reduce anxiety via help, advice and the support of family members and friends. Secondly, the vicarious experience of the SCT, via advertising contexts which present older adults as role models able to deal with any e-service, can be used as a source of self-efficacy. The consequences of a communication policy will favour active aging, social participation and the independence of older adults concerning ICT, which allows reducing public spending on dependence. For example, e-services such as e-Health or telecare have shown the potential to increase the efficiency of health and long-term care systems, and lead to cost savings (European Commission, 2015:8). Also, ICT and e-services use by older and elderly citizens may have the potential to increase their quality of life (Doyle et al., 2014) by improving the relationship with the family as well as improving inclusion in the society (Guner and Acarturk, 2018). 
Regarding companies, older adults are a relevant market because of their continuous growth, due to the increase of life expectancy, and their economic capacity. The stereotype of older adults out of touch with ICT does not seem true, as there are now different behaviours within this population. Those who are surer of themselves reduce their level of anxiety, as seems to happen with older men, so they can be more involved in the use of eServices in general. Those who are more insecure, both intrinsically and as a result of perceived risks, will stay away from the commercial practices which produce anxiety in them. This is why, when designing training for older adults, we must try not only to improve the person's technical skills for its use, but also the perception that they are capable of successfully performing certain activities. E-services may be easier for the older adult through intuitive designs, and with appropriate signs and directions to avoid mistakes. This would let them know that they are doing the right things, so their confidence can be reinforced (Lee and Coughlin, 2015). On the other hand, one of the barriers for using eservices cited by older adults is the lack of a benefit or perceived usefulness (Wagner et al., 2010). Therefore, companies must demonstrate to them that this e-service is useful in their daily life, for example using explanatory booklets, ads and generating positive word-ofmouth. Regarding the environment - which family and friends are part of - we have also demonstrated that this influences people's self-perceptions and their behaviour. Social persuasions and vicarious experience, related with the use of any e-Service can contribute to increasing self-efficacy and enables older adults to experience lower levels of anxiety (Karavidas, Lim and Katsikas, 2005). Also, the perceived risks of the use of the e-service positively influence anxiety and reduce its use. To reduce anxiety, we must ensure a safe, trustworthy, simple and private digital environment for older users. Thus, companies must communicate clearly the usability, the guarantees and the safety which their e-Service 
offers, underlining the benefits which are obtained from using it and considering the older adult's own circumstances.

\section{Conclusions and future research}

To sum up, older adults is one of the segments where ICT use is increasing most. Despite this, there remains an important gap in the rates of penetration of technologies for older adults in comparison with other age groups This indicates that there is a digital divide, which includes demographic elements (i.e. age, gender, income) but also others which are more psychological (i.e. self-perceptions, anxiety, self-efficacy). This study aims to explain the use of IBS by older adults, taking as its core people and their self-perceptions - one of the main barriers. We find that self-efficacy positively influences the perceived usefulness and the use of IBS and that anxiety logically reduces this use. Moreover, we find that there are important differences between self-efficacy and anxiety when we refer to technology in general compared to focusing on a specific e-Service as IBS. Also, we have noted an important role of the environment as a booster to overcome the barriers which may appear due to these self-perceptions. Finally, we found differences by gender in the behaviour and use of IBS by older adults.

This research has contributed to an understanding of the relationship between anxiety and self-efficacy in older adults, giving importance to going beyond the factors considered in other models of acceptance of technologies when understanding the adoption and use of a specific e-service. The importance of accounting for gender differences is highlighted and some concrete examples of how to use the findings are provided to improve and increase older adults' use of IBS and other e-Services. 
In future research we will increase the scope of the sample by adding groups of people with different demographic characteristics that explain differences in the acceptance and use behaviour of IBS. In addition, we will test the behaviour of the elderly in other types of eservices (more hedonic and with less perceived risk) in order to extend the results obtained.

\section{References}

Agarwal, R., Sambamurthy, V. \& Stair, R. (2000). The evolving relationship between general and specific computer self-efficacy: an empirical investigation. Information Systems Research, 11 (4), 418- 430 (DOI: http://doi.org/d9t3d7).

Akhter, S.H. (2014). Privacy concern and online transactions: the impact of internet self-efficacy and internet involvement. Journal of Consumer Marketing, 31(2), 118-125 (DOI: https://doi.org/10.1108/JCM-06-2013-0606).

Bandura, A. (1978). Reflections on self-efficacy. In S. Rachman (ed.), Advances in Behavioral Research and Therapy, 1. Oxford: Pergamon, 237-269.

Bandura, A. (1986). Social foundations of thought and action: A social cognitive theory. Eaglewood Cliffs, NJ: Prentice-Hall, Inc.

Bandura, A. (1988). Self-efficacy conception of anxiety. Anxiety Research, 1(2), 77-98 (DOI: https://doi.org/10.1080/10615808808248222).

Bandura, A. (1989). Human agency in social cognitive theory. American psychologist, 44(9), 1175- 1184 (DOI: http://doi.org/b7wk7b).

Bandura, A. (1997). Self-efficacy: The exercise of control. New York: Macmillan. 
Barbeite, F. G. \& Weiss, E. M. (2004). Computer self-efficacy and anxiety scales for an Internet sample: testing measurement equivalence of existing measures and development of new scales. Computers in Human Behavior, 20(1), 1-15 (DOI: http://doi.org/d9b68j).

Barth, M. \& Veit, D.J. (2011). How Digital Divide affects Public E-Services: The Role of Migration Background. Wirtschaftinformatik Proceedings 2011. Paper 118.

Bauer, R. A. (1960). Consumer behavior as risk taking. In: R. S. Hancock (Ed.), Dynamic marketing for a changing World. Chicago: American Marketing Association, p.398.

Bergström, A. (2015). Online privacy concerns: A broad approach to understanding the concerns of different groups for different uses. Computers in Human Behavior, 53, 419426 (DOI: http://doi.org/bbg9).

Bhattacherjee, A. (2001). Understanding information systems continuance: an expectation-confirmation model. MIS quarterly, 351-370 (DOI: http://doi.org/bzrw25).

Blank, G., Bolsover, G. \& Dubois, E. (2014). A new privacy paradox: Young people and privacy on social network sites. Oxford: Oxford Internet Institute, University of Oxford. Global Cyber Security Capacity Centre: Draft Working Paper.

Büchi, M., Just, N. \& Latzer, M. (2015). Modeling the second-level digital divide: A five-country study of social differences in Internet use. New Media \& Society, September, 9 (DOI: http://doi.org/bbg8). 
Cazan, A. M., Cocoradã, E. \& Maican, C. I. (2016). Computer anxiety and attitudes towards the computer and the internet with Romanian high-school and university students. Computers in Human Behavior, 55, 258-267 (DOI: http://doi.org/bbg7).

Çelik, H. (2011). Influence of social norms, perceived playfulness and online shopping anxiety on customers' adoption of online retail shopping: An empirical study in the Turkish context. International Journal of Retail \& Distribution Management, 39(6), 390-413 (DOI: https://doi.org/10.1108/09590551111137967).

Charness, N., \& Boot, W. R. (2009). Aging and information technology use potential and barriers. Current Directions in Psychological Science, 18(5), 253-258 (DOI: http://doi.org/bk3946).

Chen, L. Y., Hsiao, B., Chern, C. C., \& Chen, H. G. (2014). Affective mechanisms linking Internet use to learning performance in high school students: A moderated mediation study. Computers in Human Behavior, 35, 431-443 (DOI: https://doi.org/10.1016/j.chb.2014.03.025).

Chen, K., \& Chan, A. H. (2014). Predictors of gerontechnology acceptance by older Hong Kong Chinese. Technovation, 34(2), 126-135 (DOI: http://doi.org/v7d).

Chen, R., \& He, F. (2003). Examination of brand knowledge, perceived risk and consumers' intention to adopt an online retailer. Total Quality Management and Business Excellence, 14(6), 677-693 (DOI: http://doi.org/c3j7f5). 
Chu, R. J. C. (2010). How family support and Internet self-efficacy influence the effects of e-learning among higher aged adults-Analyses of gender and age differences. Computers \& Education, 55(1), 255-264 (DOI: http://doi.org/dghfhd).

Chua, S. L., Chen, D.-T. \& Wong, A. F. (1999). Computer anxiety and its correlates: a meta-analysis. Computers in Human Behavior, 15(5), 609-623. (DOI: http://doi.org/bjk32t).

Chung, J., Park, N., Wang, H, Fulk, J. \& McLaughlin, M. (2010). Age differences in perceptions of online community participation among non-users: An extension of the Technology Acceptance Model. Computers in Human Behaviour, 26, 1674-1684 (DOI: https://doi.org/10.1016/j.chb.2010.06.016).

Compeau, D. R., \& Higgins, C. A. (1995). Computer self-efficacy: Development of a measure and initial test. MIS quarterly, 189-211 (DOI: http://doi.org/cj6p9n).

Compeau, D., Higgins, C. A. \& Huff, S. (1999). Social cognitive theory and individual reactions to computing technology: A longitudinal study. MIS Quarterly, vol. 23(2), 145-158 (DOI: http://doi.org/d8j42d).

Czaja, S. J., Charness, N., Fisk, A. D., Hertzog, C., Nair, S. N., Rogers, W. A. \& Sharit, J. (2006). Factors predicting the use of technology: findings from the Center for Research and Education on Aging and Technology Enhancement (CREATE). Psychology and aging, 21(2), 333 (DOI: http://doi.org/bcj8t6).

Damant, J. \& Knapp, M. (2015). What are the likely changes in society and technology which will impact upon the ability of older adults to maintain social (extra- 
familial) networks of support now, in 2025 and in 2040? Future of ageing: evidence review, London, UK: Government Office for Science.

Davis, F. D. (1989). Perceived usefulness, perceived ease of use, and user acceptance of information technology. MIS Quarterly, 319-340.

Dewan, S. \& Riggins, F.J. (2005). The digital divide: Current and future research directions. Journal of the Association for Information Systems, 6 (12), 298-337.

Doyle, J., Bailey, C., Scanaill, C. N. \& van den Berg, F. (2014). Lessons learned in deploying independent living technologies to older adults' homes. Universal Access in the Information Society, 13(2), 191-204 (DOI: https://doi.org/10.1007/s10209-013-0308-1).

Eastin, M.A. (2002). Diffusion of e-commerce: an analysis of the adoption of four e-commerce activities. Telematics and Informatics, 19 (3) 251-267 (DOI: http://doi.org/bvfxdd).

Eastin, M.A. \& LaRose, R.L. (2000). Internet self-efficacy and the psychology of the digital divide. Journal of Computer Mediated Communication 6 (1), Available at: http://www.ascusc.org/jcmc/vol6/issue1/eastin.html.

European Commission (2015). Growing the European Silver Economy. Background paper. Retrieved April 2019: http://ec.europa.eu/research/innovationunion/pdf/active-healthy-ageing/silvereco.pdf 
European Commission (2016). Independent living in an ageing society through innovative ICT solutions. Available at: http://cordis.europa.eu/article/id/400060independent-living-in-an-ageing-society-through-ict_es.html

Eurostat (2016). Information Society Statistics. Available at: http://www.ontsi.red.es/ontsi/es/indicador/individuos-que-usan-internet-para-banca-porinternet

Featherman, M. S., \& Hajli, N. (2015). Self-Service Technologies and e-Services Risks in Social Commerce Era. Journal of Business Ethics, 1-19 (DOI: http://doi.org/bbg5).

Featherman, M. S. \& Pavlou, P. A. (2003). Predicting e-Services adoption: a perceived risk facets perspective. International Journal of Human-Computer Studies, 59(4), 451-474 (DOI: http://doi.org/bfqnt5).

Fishbein, M., \& Ajzen, I. (1975). Belief, attitude, intention and behavior: An introduction to theory and research. Reading, MA: Addison-Wesley.

Fornell, C., \& Larcker, D. F. (1981). Evaluating structural equation models with unobservable variables and measurement error. Journal of Marketing Research, 39-50 (DOI: http://doi.org/cwp).

Forsythe, S., Liu, C., Shannon, D., \& Gardner, L. C. (2006). Development of a scale to measure the perceived benefits and risks of online shopping. Journal of Interactive Marketing, 20(2), 55-75 (DOI: https://doi.org/10.1002/dir.20061). 
Friemel, T. N. (2014). The digital divide has grown old: Determinants of a digital divide among seniors. New Media \& Society, June 12 (DOI: http://doi.org/wnb).

Gelbrich, K., \& Sattler, B. (2014). Anxiety, crowding, and time pressure in public self-service technology acceptance. Journal of Services Marketing, 28(1), 82-94. (DOI: http://doi.org/v7f).

Guner, H., \& Acarturk, C. (2018). The use and acceptance of ICT by senior citizens: a comparison of technology acceptance model (TAM) for elderly and young adults. Universal Access in the Information Society, 1-20. (DOI: https://doi.org/10.1007/s10209$\underline{018-0642-4)}$

Guo, X., Sun, Y., Wang, N., Peng, Z. \& Yan, Z. (2013). The dark side of elderly acceptance of preventive mobile health services in China. Electronic Markets, 23(1), 49-61. (DOI: http://doi.org/v7h).

Hair Jr. F., J., Sarstedt, M., Hopkins, L. \& G. Kuppelwieser, V. (2014). Partial least squares structural equation modeling (PLS-SEM) An emerging tool in business research. European Business Review, 26(2), 106-121 (DOI: http://doi.org/bbgb).

Henseler, J. (2012). PLS-MGA: A non-parametric approach to partial least squaresbased multi-group analysis. In Challenges at the interface of data analysis, computer science, and optimization (pp. 495-501). Springer, Berlin, Heidelberg.

Henseler, J., Hubona, G. \& Ray, A. (2015). Using PLS Path Modeling in New Con formato: Español (alfab. internacional) Technology Research: Updated Guidelines, Industrial Management \& Data Systems, 116 (1), 2-20. (DOI: http://doi.org/bbpk).Henseler, J., Ringle, C. M. \& Sarstedt, M. (2015). A 
new criterion for assessing discriminant validity in variance-based structural equation modeling. Journal of the Academy of Marketing Science, 43, 115-135 (DOI: http://doi.org/bbg4).

Hernández, B., Jiménez, J. \& Martín, M. J. (2011). Age, gender and income: do they really moderate online shopping behaviour? Online Information Review, 35(1), 113133 (DOI: http://doi.org/d7qgz2).

Hill, W. W., Beatty, S. E. \& Walsh, G. (2013). A segmentation of adolescent online users and shoppers. Journal of Services Marketing, 27(5), 347-360 (DOI: http://doi.org/bbg3).

Hsu, M. H. \& Chiu, C. M. (2004). Internet self-efficacy and electronic service acceptance. Decision Support Systems, 38(3), 369-381 (DOI: https://doi.org/10.1016/j.dss.2003.08.001).

International Telecommunication Union, ITU (2015). Measuring the Information Society Report. Available at: http://www.itu.int/en/ITUD/Statistics/Documents/publications/misr2015/MISR2015-w5.pdf.

Karavidas, M., Lim, N. K. \& Katsikas, S. L. (2005). The effects of computers on older adult users. Computers in Human Behavior, 21(5), 697-711 (DOI: http://doi.org/cr8599).

Kavathatzopoulos, I. (2015). ICT and sustainability: skills and methods for dialogue and policy making. Journal of Information, Communication and Ethics in Society, 13(1), 13-18. (DOI: http://doi.org/bbnv) 
Kulviwat, S., C. Bruner II, G. \& P. Neelankavil, J. (2014). Self-efficacy as an antecedent of cognition and affect in technology acceptance. Journal of Consumer Marketing, 31(3), 190-199 (DOI: http://doi.org/bbg2).

Kwon, O. \& Wen, Y. (2010). An empirical study of the factors affecting social network service use. Computers in Human Behavior, 26(2), 254-263 (DOI: http://doi.org/gzs).

Lam, J. C. \& Lee, M. K. (2006). Digital inclusiveness--Longitudinal study of Internet adoption by older adults. Journal of Management Information Systems, 22(4), 177206 (DOI: http://doi.org/frtjhv).

Lankton, N. K., \& Wilson, E. V. (2007). Factors influencing expectations of ehealth services within a direct-effects model of user satisfaction. e-Service Journal, 5(2), 85-111 (DOI: http://doi.org/c7b63c).

Lee, C. L., \& Huang, M. K. (2014). The influence of computer literacy and computer anxiety on computer self-efficacy: the moderating effect of gender. Cyberpsychology, Behavior, and Social Networking, 17(3), 172-180 (DOI: http://doi.org/bbgx).

Lee, M.-C. (2009). Factors influencing the adoption of internet banking: An integration of TAM and TPB with perceived risk and perceived benefit. Electronic Commerce Research and Applications, 8(3), 130-141 (DOI: http://doi.org/dqb7w7). 
Lee, C., \& Coughlin, J. F. (2015). PERSPECTIVE: Older adults' adoption of technology: an integrated approach to identifying determinants and barriers. Journal of Product Innovation Management, 32(5), 747-759.

Leppel, K., \& McCloskey, D. W. (2011). A cross-generational examination of electronic commerce adoption. Journal of Consumer Marketing, 28(4), 261-268 (DOI: http://doi.org/cpjf6k).

Macedo, I. M. (2017). Predicting the acceptance and use of information and communication technology by older adults: An empirical examination of the revised UTAUT2. Computers in Human Behavior, 75, 935-948 (DOI:

http://dx.doi.org/10.1016/j.chb.2017.06.013)

Marakas, G. M., Johnson, R. D. \& Palmer, J. W. (2000). A theoretical model of differential social attributions toward computing technology: when the metaphor becomes the model. International Journal of Human-Computer Studies, 52(4), 719-750 (DOI: http://doi.org/b24nd2).

Meuter, M.L., Ostrom, A.L., Bitner, M.J. \& Roundtree, R. (2003). The influence of technology anxiety on consumer use and experiences with self-service technologies. Journal of Business Research, 56 (11), 899-906. (DOI: http://doi.org/fh2hzz).

Nayak, L. U., Priest, L. \& White, A. P. (2010). An application of the technology acceptance model to the level of Internet usage by older adults. Universal Access in the Information Society, 9(4), 367-374 (DOI: http://doi.org/cn2cpv). 
Neill, W. D., \& Richard, J. E. (2012). Intranet portals: marketing and managing individuals' acceptance and use. Australasian Marketing Journal, 20(2), 147-157 (DOI: https://doi.org/10.1016/j.ausmj.2011.10.003).

Niehaves, B., \& Plattfaut, R. (2014). Internet adoption by the elderly: employing IS technology acceptance theories for understanding the age-related digital divide. European Journal of Information Systems, 23(6), 708-726 (DOI: http://doi.org/bbgs).

Niemelä-Nyrhinen, J. (2007). Baby boom consumers and technology: shooting down stereotypes. Journal of Consumer Marketing, 24(5), 305-312. (DOI: http://doi.org/d54hjh).

Organisation for Economic Cooperation and Development (OECD, 2001). Understanding the digital divide. Paris. http://www.oecd.org/dataoecd/38/57/1888451.pdf (22-01-2015).

Page, K. L., Robson, M. J. \& Uncles, M. D. (2012). Perceptions of web knowledge and usability: When sex and experience matter. International Journal of Human-Computer Studies, 70(12), 907-919 (DOI: http://doi.org/bbgr).

Pajares, F. (2002). Overview of social cognitive theory and of self-efficacy. Retrieved October 2015, from http://www.emory.edu/EDUCATION/mfp/eff.html

Peral-Peral, B., Arenas-Gaitán, J., \& Villarejo-Ramos, Á. F. (2015). From Digital Divide to Psycho-digital Divide: Elders and Online Social Networks. Comunicar, 23(45), 57-64 (DOI: http://doi.org/bbgp). 
Powell, A. L. (2013). Computer anxiety: comparison of research from the 1990s and 2000s. Computers in Human Behavior, 29, 2337-2381 (DOI: http://doi.org/w4z).

Ringle, C. M., Wende, S. \&Becker, J.-M. (2015). "SmartPLS 3.2.3" Boenningstedt: SmartPLS GmbH, http://www.smartpls.com

Rowley, J. (2008). Understanding digital content marketing. Journal of Marketing Management, 24(5-6), 517-540 (DOI: https://doi.org/10.1362/026725708X325977).

Scherer, R., Siddiq, F. \& Teo, T. (2015). Becoming more specific: Measuring and modeling teachers' perceived usefulness of ICT in the context of teaching and learning. Computers \& Education, 88, 202-214 (DOI: http://doi.org/bbgn).

Sum, S., Mathews, R. M., Hughes, I. \& Campbell, A. (2008). Internet use and loneliness in older adults. CyberPsychology \& Behavior, 11(2), 208-211 (DOI: 10.1089/cpb.2007.0010).

Sun, H. \& Zhang, P. (2006). The role of moderating factors in user technology acceptance. International Journal of Human-Computer Studies, 64 (2), 53-78 (DOI: http://doi.org/fs9tft).

Thatcher, J. B., \& Perrewé, P. L. (2002). An empirical examination of individual traits as antecedents to computer anxiety and computer self-efficacy. MIS Quarterly, vol. 26(4), 381-396 (DOI: http://doi.org/ckv982). 
Thatcher, J., Loughry, M., Lim, J. \& McKnight, H. (2007). Internet anxiety: an empirical study of the effects of personality, beliefs, and social support. Information \& Management, 44(4), 353-363 (DOI: http://doi.org/ddqwft).

Torkzadeh, G., \& Van Dyke, T. P. (2002). Effects of training on Internet selfefficacy and computer user attitudes. Computers in Human Behavior, 18(5), 479-494 (DOI: http://doi.org/fp7kzc).

Tsai, C. H. (2014). Integrating social capital theory, social cognitive theory, and the technology acceptance model to explore a behavioral model of telehealth systems. International Journal of Environmental Research and Public Health, 11(5), 4905-4925 (DOI: http://doi.org/bbgm)

Tsai, H.S., Shillair, R., Cotton, S.R., Winstead, V. \& Yost, E. (2015). Getting Grandma Online: Are Tablets the Answer for Increasing Digital Inclusion for Older Adults in the U.S.? Educational Gerontology (DOI: http://doi.org/bbgi).

United Nations (2017). World Population Prospects. The 2017 Revision. Available at: https://esa.un.org/unpd/wpp/Publications/Files/WPP2017_KeyFindings.pdf

Valenduc, G., Brotcorne, P., Lotte Damhuis, V.L. \& Vendramin, P. (2010). The second order digital divide research. CONTRACT FTU - FONDATION TRAVAILUNIVERSITÉ (Namur)

Van Deursen, A., \& Van Dijk, J. (2011). Internet skills and the digital divide. New Media \& Society, 13(6), 893-911 (DOI: http://doi.org/fjqc43). 
Venkatesh, V. (2000). Determinants of perceived ease of use: Integrating control, intrinsic motivation, and emotion into the technology acceptance model. Information Systems Research, 11(4), 342-365 (DOI: http://doi.org/cdt).

Venkatesh, V. \&Morris, M.G. (2000). Why don’t men ever stop to ask for directions? Gender, social influence, and their role in technology acceptance and usage behavior. MIS Quarterly, Vol. 24 No. 1, pp. 115-39 (DOI: http://doi.org/cdw).

Venkatesh, V., \& Davis, F. D. (1996). A model of the antecedents of perceived ease of use: Development and test. Decision Sciences, 27(3), 451-481 (DOI: http://doi.org/cc7nt2).

Venkatesh, V., Morris, M. G., Davis, G. B. \& Davis, F. D. (2003). User acceptance of information technology: Toward a unified view. MIS Quarterly, 27(3), 425-478.

Venkatesh, V., Thong, J. Y. \& Xu, X. (2012). Consumer acceptance and use of information technology: extending the unified theory of acceptance and use of technology. MIS Quarterly, 36(1), 157-178.

Vošner, H. B., Bobek, S., Kokol, P. \& Krečič, M. J. (2016). Attitudes of active older Internet users towards online social networking. Computers in Human Behavior, 55, 230241 (DOI: http://doi.org/bbgg).

Vroman, K. G., Arthanat, S. \& Lysack, C. (2015). “Who over 65 is online?” Older adults' dispositions toward information communication technology. Computers in Human Behavior, 43, 156-166 (DOI: http://doi.org/bbgd). 
Wagner, N., Hassanein, K. \& Head, M. (2010). Computer use by older adults: A multi-disciplinary review. Computers in Human Behavior, 26(5), 870-882 (DOI: http://doi.org/b2h7tx).

Walker, R. H., \& Johnson, L. W. (2006). Why consumers use and do not use technology-enabled services. Journal of Services Marketing, 20(2), 125-135 (DOI: http://doi.org/dtwxs2).

Wei, K. K., Teo, H. H., Chan, H. C., \& Tan, B. C. (2011). Conceptualizing and testing a social cognitive model of the digital divide. Information Systems Research, 22(1), 170-187 (DOI: http://doi.org/d974qx).

World Economic Forum (2016). The Global Information Technology Report 2016. Innovating in the Digital Economy. Available at: http://goo.gl/pivGLm.

Wu, Y. T., \& Tsai, C. C. (2006). University students' internet attitudes and Internet self-efficacy: a study at three universities in Taiwan. CyberPsychology \& Behavior, 9(4), 441-450 (DOI: http://doi.org/c3whf7).

Yang, Y., Liu, Y., Li, H. \& Yu, B. (2015). Understanding perceived risks in mobile payment acceptance. Industrial Management \& Data Systems, 115(2), 253-269 (DOI: http://doi.org/bbgc).

Yao, C., \& Liao, S. (2011). Measuring the antecedent effects of service cognition and internet shopping anxiety on consumer satisfaction with e-tailing service. Management \& Marketing, 6(1), 59-78. 
Zhao, X., Mattila, A. S. \& Tao, L.-S. E. (2008). The role of post-training selfefficacy in customers' use of self-service technologies. International Journal of Service Industry Management, 19(4), 492-505. (DOI: $\underline{\text { http://doi.org/cfz8cv). }}$ 